\title{
A multidisciplinary approach for the physic-chemical characterization of peloids to new perspectives in the development for "hydrothermal Developing Countries" using partecipatory methodology
}

\author{
ROSSI Davide ${ }^{1,2,3}$, URUCI Renata ${ }^{1,2}$
}

Editor: Mihail HOTETEU, Romanian Association of Balneology, hoteteu@yahoo.com

Reviewers: Constantin Munteanu and Gabriela Dogaru

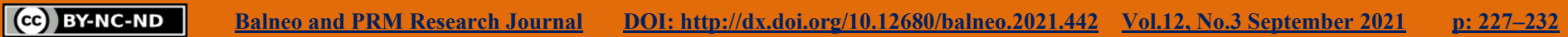

*Corresponding author: ROSSI Davide ,email: davide.rossi.bazh@gmail.com;

1. "Development Cooperation BAZH NGO", Tirana, Albania

2. "Development Cooperation Italia BAZH.I", Maserada Sul Piave, Italia

3. Department of Pharmaceutical and Pharmacological Sciences, University of Padova

\begin{abstract}
The Osservatorio Termale Permanente (OTP) operated from 1996 to 2014 in the Italian and international therapeutic thermalism field. The main aim of OTP was the development of a multidisciplinary approach for the characterization of the quality of peloids for cutaneous application and their maturation process using different qualitative and quantitative analytic techniques opening at the Integrated Analytical Approach in the field of therapeutic thermalism. The main innovation introduced by OTP were rheology and surface tensiometry applications on peloids. The introduction of surface tensiometry included the skin as a fundamental element for the development of mud therapy protocols based on the bioadhesive properties of peloids. The interfacial investigations between peloids and skin led to the characterization of the exchange activity occurring during pelotherapy on the cutaneous surface in a non-invasive and fast way. On these bases, our work linked each other the multidisciplinarity approach to the study of hydrothermal resources performed by OTP with the concept of the participative methodology commonly applied to the development of projects in the field of development cooperation. This combined approach led us to develop a scientific proposal for the development of therapeutic thermalism in countries not yet improved in this field and characterized by the presence of hydrothermal resources.
\end{abstract}

Keywords: peloid, surface tensiometry, Rossi factor, rheology, Rheological Termal Mud, skin, integrated analytical approach, participative methodology, therapeutical thermal proposal, hydrothermal development countries

\section{INTRODUCTION}

Research projects must provide wide views in the characterization of complex systems and concerning the processes involving them. In the case of the hydrothermal field for therapeutic aims, the principal analytic techniques commonly used for the characterization of peloids there are ICP-MS (Inductively Coupled Plasma Mass Spectrometry), FAAS (Flame Atomic Absorption Spectrometry), CVASS (Cold Vapour Atomic Absorption Spectrometry), and EDS (Energy Dispersion Spectrometry) (1). The peloids investigations are using SEM (Scanning Electronic Microscope). The mineralogic components were studied by XRD (X-rays diffractometer) and X-ray fluorescence (XRF) (1). The Osservatorio Termale Permanente - OTP (1996-2014) introduced the rheology and surface tensiometry in the therapeutic thermal research field within the frame of a project focused on natural and formulation systems for cutaneous and mucous applications. The project was closed to a subproject of biotechnological researches applied to the thermal field (2). The activities of OTP performed studies on the maturation process of peloids and their quality. The OTP developed reproducible protocols in pelotherapy using the integrated analytical approach (IAA) (2). This goal was reached by the development of a method for the control of the maturation process of peloids founded on the correlation between their chemistry-mineralogy, structure, and surface (2). Based on the IAA concept, the maturation process of peloids, their qualification, and the development of reproducible therapeutic protocols are closed to an integrated scientific network. The integrated scientific network is a general term that underlines the participative methodology applied in a research field. The one method, commonly used in the development cooperation field (3), involves different national and international experts in physic, chemistry, and clinic areas related to the therapeutic thermal area. The development of innovative thermal therapy protocols for the improvement of health\&wellness of patients should be closed to the link existing between all physic-chemical aspects of the peloids using IAA (2). The first aim of our work is to provide an overview of the principal research methodologies applied to the investigations of peloids from a generic thermal area (TA) performed by the PTO from 1996 to 2014. The second is a proposal for the IAA concept in competitiveness countries in the therapeutic thermalism market using the participatory methodology (PM). These countries, characterized by hydrothermal 
resources, were here defined as "Hydrothermal Developing Countries". On this basis, the work was separated into two sections, one related to the scientific aspects of therapeutic thermalism, and the other one dedicated to the project idea developed here.

\section{Scientific section}

From 1995 to 2014 the OTP investigated peloids and spring waters using chemical, rheological, and surface free energy analytical tools to developing a first specific thermal multidisciplinary Protocol (TMP). Particularly during 1995-2005, OTP improved the research toward the chemical-mineralogical and rheological characterizations of peloids. During 2005-2014, OTP started to investigate the surface free energy properties of peloids and surface tension of spring waters within the chemical-structure-surface correlations under the coordination of the Technical Director Dr. Davide Rossi. Within the introduction of surface tensiometry, from 2005 to 2014 the activities of OTP activities the TMP evolved to Integrated Analytical Approach (IAA).

\subsection{Material and method.}

Before the definition of IAA, TMP was enriched over time with toxicologic, morphologic, difractometric, and fluorescence investigations (1).

\subsubsection{Chemical analysis}

The chemical analysis was using ICP-MS (Inductively Coupled Plasma Mass Spectrometry), FAAS (Flame Atomic Absorption Spectrometry), CVASS (Cold Vapour Atomic Absorption Spectrometry), EDS (Energy Dispersion Spectrometry), and XRF (X-ray Fluorescence) (1). The peloid was investigated by SEM (Scanning Electronic Microscope), XRD (X-rays diffractometer), and the toxicity was analyzed using Microtox Test (1). The ICP-MS provided information about $\mathrm{Al}, \mathrm{Ba}, \mathrm{Li}, \mathrm{Co}, \mathrm{Cu}, \mathrm{Mn}, \mathrm{Ni}$, and $\mathrm{Zn}$, FAAS provided data of $\mathrm{Ca}, \mathrm{Mg}, \mathrm{Na}, \mathrm{K}$, and $\mathrm{Fe}$, CVAAS provided a quantitative profile of $\mathrm{Hg}$ (1). These analyses were performed directly on spring waters and peloids after mineralization. The XRF provided quantitative and qualitative information on the peloid sample. The qualitative investigations were on the recognition of $\mathrm{X}$ ray that is typical of each chemical element emitted when irradiated by radiation with an appropriate wavelength. The quantitative analysis is base on the principle of proportionality between the intensity of a characteristic emission and the concentration of the emitter chemical element. The toxicity of peloids was measure following the decrease of the vitality of Photobacterium Phosphoreum (1). The variation of the bioluminescence was analyzed using a 490nm photometer (1). SEM/EDX investigations used graphite as a conductive metallic coverage, while XRD analysis was after the washing, filtering, and drying sample (1).

\subsubsection{Rheological analysis}

The viscoelastic properties of peloids were investigated at $20^{\circ} \mathrm{C}$ using a rotational rheometer equipped with PP35 sensors coupled with a thermostat (2). The rheological investigations were performed using $2 \mathrm{~mm}$ of the gap at 1 $\mathrm{Hz}$ frequency and varying the stress from 0 to $1000 \mathrm{~Pa}$ (2). The frequency sweep was measure in the range of 0.0464-25.1 Hz. This range provided parameters of $\mathrm{G}^{*}$, $\delta$, and rheological parameters that characterize the microstructural profile of the peloid (2).

\subsubsection{Surface tensiometry analysis}

OTP started investigations of surface free energy (SFE: $\mathrm{mJ} / \mathrm{m} 2$ ) of peloids for therapeutic use in 2005. The analysis of the surface free energy of peloids was performed using a tensiometer equipped with syringes charged with liquid tests having different polar characteristics (4). The liquid test used was perfluoropolyether Fomblin HC/25®PFPE, diiodomethane, and glycerine (4). The wettability of peloids samples was determined using the contact angle (CA: deg) method while their SFE, dispersion component (DC: $\mathrm{mJ} / \mathrm{m} 2$ ), and polar component (PC: $\mathrm{mJ} / \mathrm{m} 2$ ) were measure using Owens-Wendt\&RabelKaelbe (OWRK) mathematical conversion model (5). The CA of PFPE was measure using the Rossi factor $(f)$ after $<0.5 \mathrm{~s}$ from the contact with the peloid surface (Equation 1) (6).

$f=\mathrm{S}(\mathrm{px}) / \mathrm{t}(\mathrm{s})$

where $f$ is Rossi factor, $\mathrm{S}$ is drop image sharpness (px) of liquid test and $\mathrm{t}$ is drop image snapshot time (s). The Rossi factor led to the development of TVS mud index (7), a dimensionless integrated surface tensiometry index capable to determine the surface free energy properties of a peloid in relation to its biological maturation process.

\subsection{Results and discussions.}

The frequencies of the chemical elements of peloids $(\mathrm{N}=7)$ are in Figures $1 \mathrm{a}$ and $1 \mathrm{~b}$, while Figures $1 \mathrm{c}$ and $1 \mathrm{~d}$ report the concentration of the chemical elements (1).

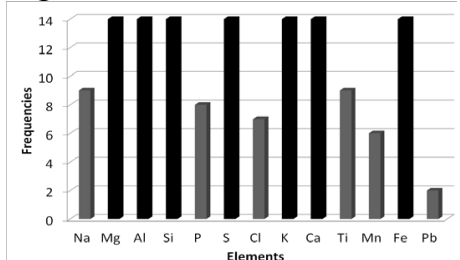

Fig. 1a. Total frequencies of elements

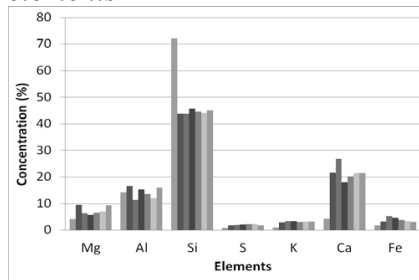

Fig. 1c. Concentration of main elements

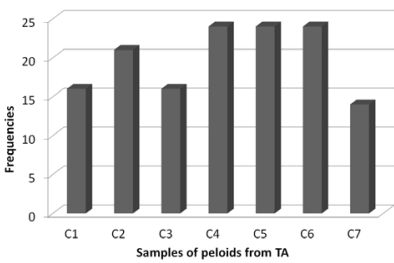

Fig. 1b. Variability of elements in each sample

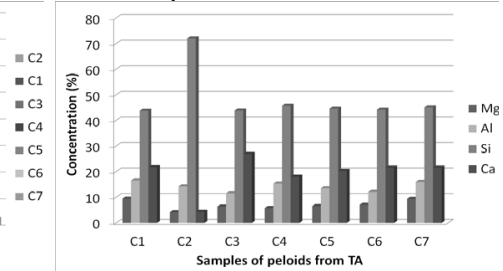

Fig. 1d. Variability of

$\mathrm{Mg}, \mathrm{Al}, \mathrm{Si}$, and $\mathrm{Ca}$ in each sample 
Figure 1a has represented the elements having the highest frequencies in all samples investigated (C1-C7), while Figure $1 \mathrm{~b}$ shows the high variability of the chemical elements considered in each sample. Figure 1c shows the relative abundance of the elements selected based on the results of Figure 1c, and Figure 1d represented the relative abundance of selected $\mathrm{Mg}, \mathrm{Al}, \mathrm{Si}$, and $\mathrm{Ca}$ elements contained in each sample of peloids collected from the TA (1). The selection of $\mathrm{Mg}, \mathrm{Al}, \mathrm{Si}$, and $\mathrm{Ca}$ as reference elements of the typical peloids from TA led to the development of the Element Reproducibility Index (ERI) $(0<\mathrm{x}<1)$ (Figure 2a and $2 \mathrm{~b}$ ).

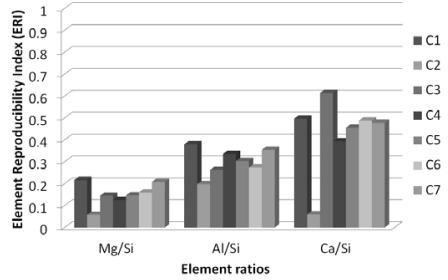

Fig. 2a: Comparison between ElementReproducibility Index (ERI) of peloids for each sample

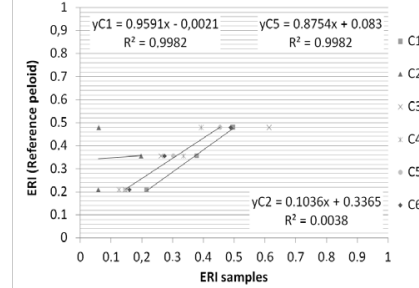

Fig. 2b: Correlation degree between Element eproducibility Index (ERI) of peloids with reference $(C 7)$

The ERI can detect which samples of peloid are characterized by the anomalous relative abundance of elements. Consequently, that kind of peloid does not represent the typical natural composition of the thermal mud collected in TA. Figure $2 b$ shown the R2 values calculated correlating the ERI values of all peloids samples with that of reference one (C7). R2 represents a parameter that assesses the modification of the quality of a peloid sample about the reference (C7). Figures $2 \mathrm{a}$ and $2 \mathrm{~b}$ demonstrated that it is possible to assess the quality of a peloid about its natural composition with a value. This method was applied to 130 spas of TA (Figure 3).

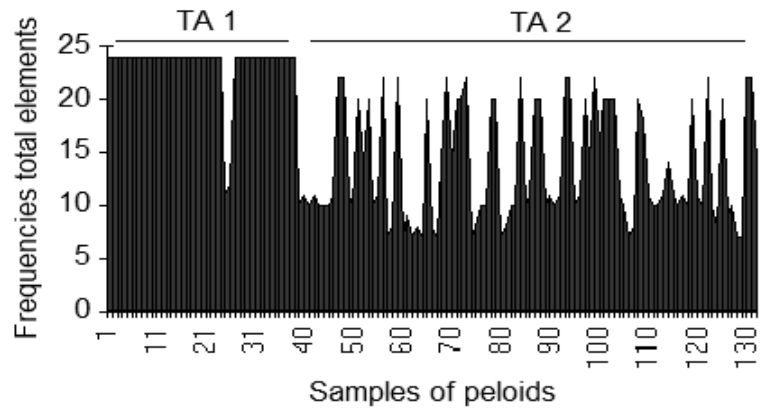

Fig. 3. Total frequencies of the inorganic compounds present in TA peloids

Figure 3 demonstrated that the peloids collected from the two-zone TA1 and TA2 presented different behavior in elements distributions (1). The smaller zone TA1 showed more reproducibility in the total frequencies of chemical elements concerning the bigger one TA2. The graph shows in Figure 3 is called Element Frequency Index (EFI). EFI demonstrated that in the spa's management of peloids there are differences in the two-zone of TA. Figures $4 \mathrm{a}, 4 \mathrm{~b}, 4 \mathrm{c}$, and $4 \mathrm{~d}$ have reported a summary view of toxic potentials, morphologic aspect, EDS, and XRD profile of peloids randomly collected from the generic TA investigated (1).

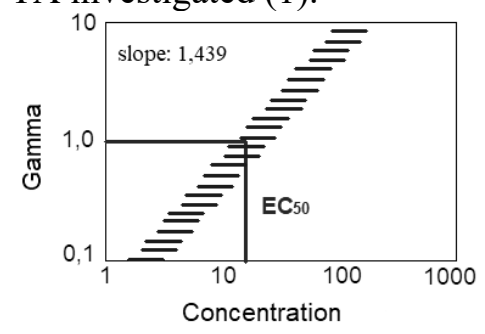

Fig. 4a. Toxicologic profile of peloids

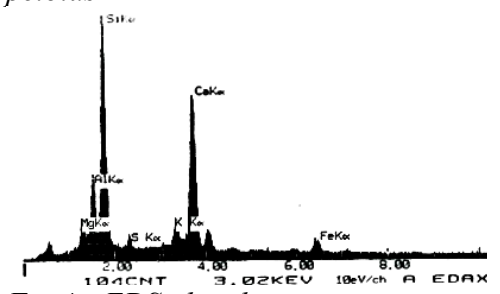

Fig.4c. EDS abundance spectra

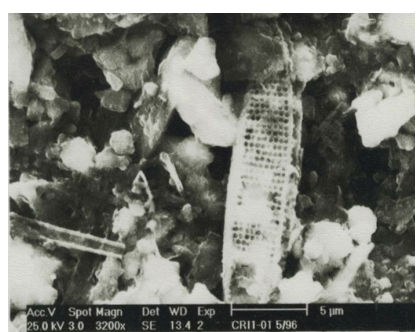

Fig.4b. SEM image of peloids

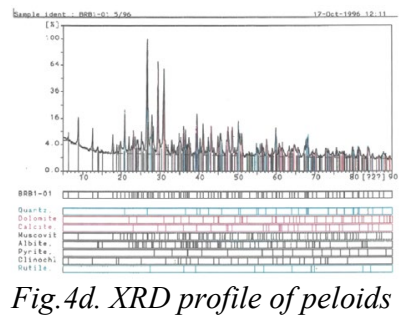

Figure 4a confirmed that peloids didn't contain toxic potentials because the EC50 is higher respect phenol $0.01 \%(\mathrm{p} / \mathrm{v})$ considered as reference parameter (1). Figure $4 \mathrm{~b}$ shows the mineralogic profile of a sample of TA peloid, and Figure $4 \mathrm{c}$ demonstrates that the principal abundance (At\%) of elements in the peloids samples are $\mathrm{Mg}, \mathrm{Al}, \mathrm{Si}$, and $\mathrm{Ca}$ that values used for the development of ERI. Figure 4d reports a typical XRD mineralogic profile of a TA peloid. Figure 5 shows the frequencies of the mineralogic phases of the peloids samples $\mathrm{C} 1-\mathrm{C} 7$, and Figure 6 shows the results related to the rheological investigations performed on reference TA peloid (C7) with its maturation process (1).

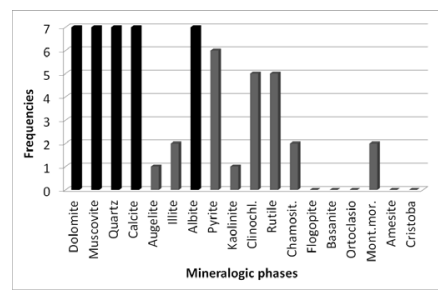

Fig.5. frequencies of mineraligic phases TA samples $\mathrm{C1}-\mathrm{C} 7$

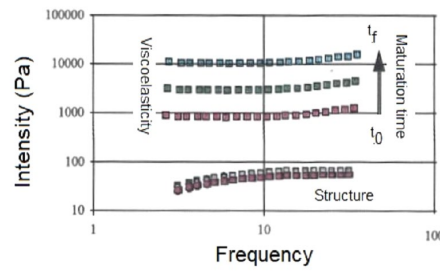

Fig.6. Assessment of maturation process of TA reference peloid using rheology
Figure 5 demonstrated that Dolomite, Muscovite, Quartz, Calcite, and Albite are present in higher levels respect other mineralogic phases in the samples of TA peloids analyzed (1). Figure 6 shows the maturation process after 45 days and the modification of the viscoelasticity properties of the TA peloid measured by Rheological Thermal Mud (RTM) (1,2). In particular, the $\mathrm{G}^{*}$ component values increased over time until their maximum value while $\delta$ levels appeared unchanged. Figures $7 \mathrm{a}, 7 \mathrm{~b}, 7 \mathrm{c}$, and $7 \mathrm{~d}$ have reported the main results obtained from the surface tensiometry studies of TA peloids (1). 


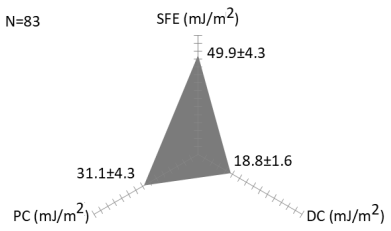

Fig. 7a. Surface Free Energy components of typical peloids from $T A$

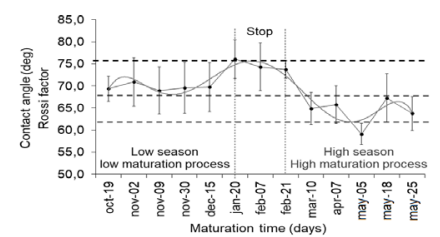

Fig. 7c. Assessment of the seasonality trend of a TA spas based on the peloid maturation process

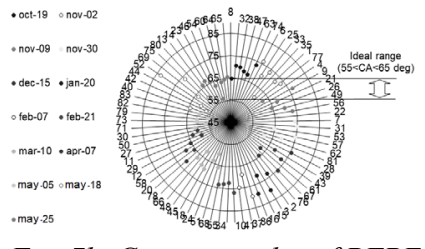

Fig. 7b. Contact angles of PFPE measured using Rossi factor on peloids surfaces during maturation process,

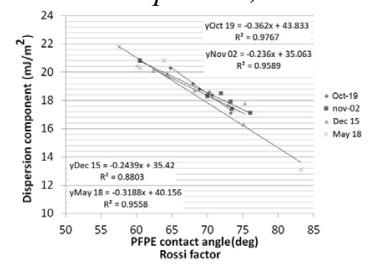

Fig. $7 d$. Correlation between $C A$ of PFPE and DC of peloids in seasonal stable state

Figure 7a represents the average SFE, DC and PC of TA peloids $(\mathrm{N}=83)$, Figure $7 \mathrm{~b}$ shown the behavior of $\mathrm{CA}$ of PFPE measured on TA peloids surfaces in different time steps during the maturation process (TVS mud index), Figure $7 \mathrm{c}$ report the seasonal activity of TA spas determined on the base of the TVS mud index values performed using Rossi factor, and Figure $7 \mathrm{~d}$ demonstrated the relationships between TVS mud index and DC of TA peloids. The surface free energy properties of TA peloids showed a strong un balancement toward the PC because of their typical high hydration state. The CA of PFPE revealed a great sensitivity in the evaluation of the maturation process due to the high correlation degree between TVS mud index and DC. As regards $\mathrm{XRF}, \mathrm{CaO}$ and $\mathrm{MgO}$ are mainly related to the carbonate components of TA peloids, while $\mathrm{Al}_{2} \mathrm{O}_{3}$ silicate phase corresponds to micaceous and clay phyllosilicates (4). Then the maturation process of the TA peloid involve the clayey fraction, $\mathrm{Al}_{2} \mathrm{O}_{3}$ was assuming as such chemical marker ( $\left.\mathrm{I}_{\text {chmi }}\right)$ for chemical assessment of TA peloid (4). Because correlation of $I_{\text {chmi }}$ with a correspondent surface tensiometry parameter, a Surface Tensiometry Index (It) was developed here (Equation 2).

\section{$\mathrm{I}_{\mathrm{t}}=\mathrm{e}^{\log R 2}$}

where $I_{t}$ is Surface Tensiometry Index and R2 is the correlation degree (R2) between CAs of glycerine, diiodomethane, and PFPE, and surface free energy parameters SFE, DC, PC of TA peloid. Figures $8 \mathrm{a}$ and $8 \mathrm{~b}$ reported the correlation degree between the $\mathrm{I}_{\mathrm{chmi}}$ index and $\mathrm{I}_{\mathrm{t}}$, and the CAs of glycerine.

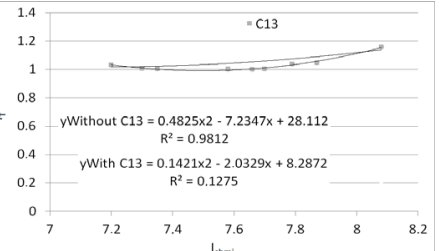

Fig. 8a. Correlation between It and Ichmi of 10 samples of TA peloids

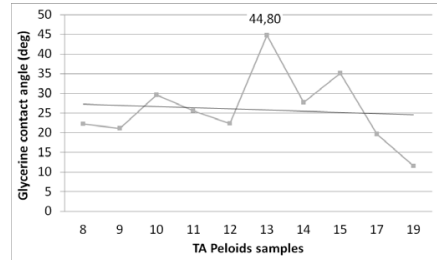

Fig. 8b. CAs of glycerine of TA peloids
Figure $8 \mathrm{a}$ demonstrated the high correlation degree $\left(\mathrm{R}^{2}=0.98\right)$ between $\mathrm{I}_{t}$ and $\mathrm{I}_{\text {chmi }}$ of TA peloids samples exceptionally $\mathrm{C} 13$ because of its anomalous CA values of glycerine liquid test (Figure 8b). The anomalous CA of glycerine was due to the low presence of water in the TA peloid that should be $\sim 35 \%$. OTP evaluated the exchange activity at the interface between skin and mature peloid during Mud Pack Treatment (MPT) (8) and after the treatment with the only clayey fraction. In Figure 9 is reported a general "invitro" and in vivo surface, tensiometry protocol for the evaluation of the functional efficacy of TA peloids to the modification of the selective permeability of skin that led to the absorption of natural therapeutic agents produced during the maturation process $(9,10)$.

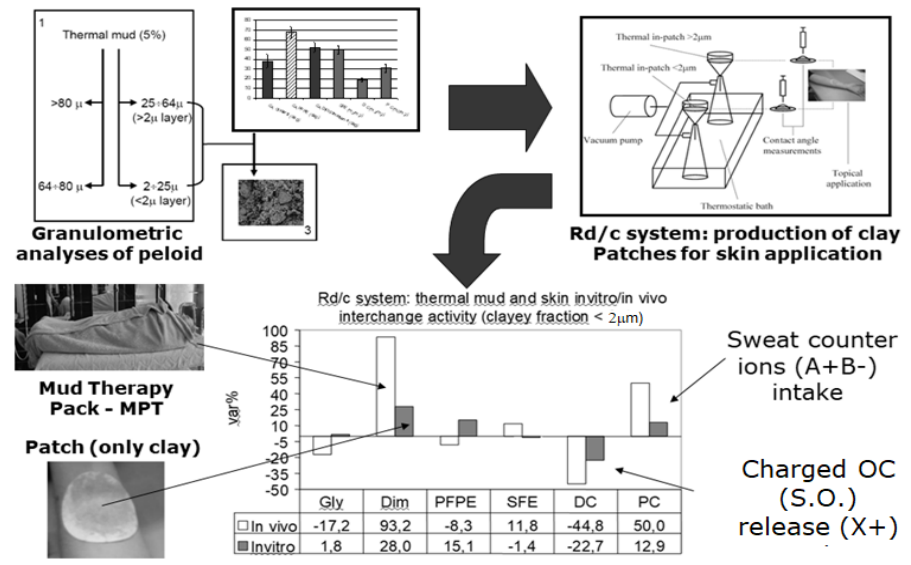

Fig. 9. Surface tensiometry invitro/invivo protocol for the evaluation of peloid/skin exchange activity

Figure 9 shows the separation of the largest particles of the peloid, the production of thermal patches, constituted by cellulose's filters used for the under vacuum separation of the finest dimension ones ( $\mathrm{Rd} / \mathrm{c}$ system), the surface tensiometry analyses of the thin stratum of the fine clayey particles deposited on the filter (9), and the application of the patches on the skin for 10 minutes (10). The application modality of the clayey patches on the skin was defined as "invitro" to distinguish it from in vitro, while the in vivo term related to the application of integral TA peloid during MPT (10). The second phase of the protocol regarded a second surface tensiometry characterization of the thin stratum of the fine clayey particles after the invitro skin application, a comparison between SFE, DC, and PC of the clayey fraction, measured before and after the invitro skin application of the patches, and the data obtained from the same sample of TA peloid before and after in vivo application during MPT (10). Figure 9 shows the decrease of the DC of the peloid after its application on the skin. This is because of the release of the organic compounds of peloid on the skin surface. Figure 9 shows an increase in the PC of the peloid due to the absorption of sweat from the skin. In the end, Figure 9 shows the increment of the CA values of the diiodomethane measured on the peloid surface because its DC was lost during MPT. 
The IAA reported here constitutes a fundamental tool for the characterization of peloids for mud pack treatment (MPT). IAA led to the control of the biological maturation process of a general peloid; its quality and suitability for cutaneous applications. The chemicalstructure-surface correlations here performed using IAA suggest the importance of the development of new scientific integrated project idea for hydrothermal developing resources countries (HDC) using the participatory methodology (PM). The association between PM and IAA could represent the base for an integrated network. The realization of the integrated network should do under the coordination of national and international experts in chemical, structure, and surface sciences. The integrated network could provide HDC with innovative technologies in order to introduce and improve local therapeutic protocols and wellness in pelotherapy and balneotherapy.

\section{Scientific proposal section}

The introduction of new scientific tools such as ERI and EFI for chemical-mineralogical assessment of peloids, RTM for their rheological evaluation, and Rossi factor (TVS mud index) for the evaluation of their surface free energy properties gave the basis for the development of our scientific proposal in the hydrothermal therapeutic field within the concept of IAA. The scientific project idea proposed here basing on a large number of thermal centers experiences present in Europe, Asia, and America, and on the increase of high quality, health\&wellness needs by the world population. Balneotherapy and MPT are applied in many countries having hydrothermal resources for the treatment of diseases such as atherothrombotic disorders (11). Therapy protocols reduce the serum levels of cytokines and consequently the inflammatory reactions in patients (11). The project idea proposed here takes inspiration from the concept of developed countries defined as "a country having the standard of living or level of industrial production well below that possible with financial or technical aid; a country that is not yet highly industrialized". On the basis of this definition, we applied the same concept to "hydrothermal developing countries" (HDC) as "a hydrothermal resources country having a standard of the hydrothermal industry well below that possible with hydrothermal research aid; a country that is not yet highly represented in terms of therapeutical thermalism". This concept is independent of the richness of a country and is based only on the level of its hydrothermal resources and how is developed in this field from scientific and economic viewpoints. The project idea has the scope to promote HDC taking into account the skin as a fundamental requisite for its realization using the IAA concept. The project idea was defined here as Therapeutic Thermalism Proposal (TTP) (Figure 10a and $10 \mathrm{~b}$ ).

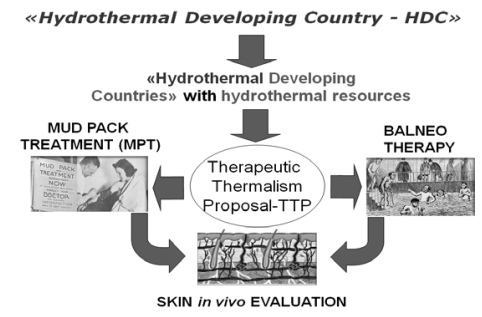

Fig. 10a. Concept of Therapeutic Thermalism Proposal (TTP)

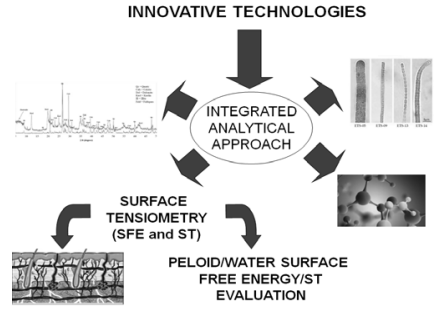

Fig.10b. Application of IAA in TTP for HDC
Figures $10 \mathrm{a}$ and $10 \mathrm{~b}$ show the association between TTP and IAA for the development of HDC, where chemicalmineralogic, biologic, rheologic, and surface properties of peloids and their surface tensiometry affinity with skin should be characterized all together based on the method for the control of maturation process of thermal muds reported in the scientific section. Figures $11 \mathrm{a}$ and $11 \mathrm{~b}$ respectively show the importance of participatory methodology (PM) for the realization of TTP and which kind of beneficiaries of HDC could be involved in the project.

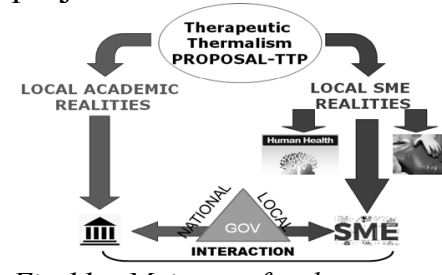

Fig. 11a. Main way for the realization of TTP

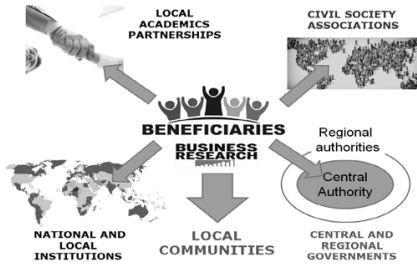

Fig. 11b. Beneficiaries of TTP/IAA combined project idea
Figure 11a shows the importance of PM in the involvement of local academic realities involving scientific sectors such as chemistry, geology, biology, microbiology, molecular medicine, and pharmaceutical. The local academic realities should improve with local small-medium enterprises (SME) in human health and local thermal spas. TTP focused on the involvement of national and local government as fundamental institutions capable of promoting the interaction between academic realities and SMEs. Figure $11 \mathrm{~b}$ demonstrates that the population must be involved in the development of TTP prioritized by central and local authorities and actors in the framework of the planning activities in the different fields of action within the hydrothermal framework resources.

\section{Conclusions}

The participative methodology should promote human resources (education, research, and productive capacity building) within the eco-sustainable development of the therapeutic hydrothermal sector in HDC within R\&D international framework. A proposal for implementing thermalism in an HDC should align performances and quality of products and services from local hydrothermal resources. A proposal should promote and enforce the research and innovation and facilitate common qualitative standards on hydrothermal resources developments. 
A proposal should produce the scientific basis for perspectives in the development and production of local peloids, qualify products and services coming from local hydrothermal resources, both for therapeutic and cosmetics aims. A proposal should promote the characterization of peloids and spring waters in their chemical, mineralogical, and physic-chemical profiles. Following the IAA concept, a proposal should also promote structural and surface energy investigations of muddy matrices and the maturation process and promote the evaluation of surface free energy of the skin and its hydration state evaluation.

A proposal should facilitate economic, social, and institutional cooperation to develop research and innovation capacity in the therapeutic hydrothermal field. In this context, a proposal should enforce the capacities at all levels of the hydrothermal health system and replace the old practices with contemporary modern practice.

In the end, a proposal should promote the knowledge economy that can contribute to economic growth and job creation in the therapeutic hydrothermal area by increasing the value of the local hydrothermal resources. The Therapeutical Thermal Proposal proposed here is based on the developed method for control of the maturation process of peloids.

The Therapeutic Thermal Proposal should rely on the availability of suitable local therapeutic thermal areas as essential ingredients for health \& wellness thermal tourism promotion.

The Therapeutic Thermal Proposal aims the involvement of all stakeholders within the therapeutic hydrothermal activity and should promote the dissemination and application of strategic innovations for human development in the therapeutic hydrothermal field using the participatory methodology, review, and assessment of existing local development and investment plans and reviewing and assessment of good practices, priorities, and different ongoing cooperation projects at the local level, and promote the sustainability is a long-term factor in which should be possible to develop a Trade Area (TA) that protect the natural heritage and ecosystem within the therapeutic hydrothermal field.

\section{Author contribution}

Dr. Davide Rossi and Dr. Renata Uruci provided respectively scientific and scientific proposal sections reported in the work

\section{Aknowledgements}

The authors wish to thank Development Cooperation BAZH NGO for technical support.

\section{References}

1. Rossi D. Sviluppo di un metodo per il controllo del processo di maturazione dei fanghi termali. Faculty of Pharmacy, Department of cellular and animal molecular biology, University of Camerino, Italy, Thesis Academic Year 1996/1997.

2. Rossi D, Dobrzyński D, Moro I, Zancato M, Realdon N. The importance of an integrated analytic approach to the study of physicochemical characteristics of natural thermal waters used for pelotherapy aims: perspectives for reusing cooled thermal waters for treatments related to thermalism applications. In: Bundschuh J, Tomaszewska B, editors. Geothermal Water Management. 1st ed. London: CRC Press; 2017

3. Rossi D, Uruci R. The 1st Albanian Catalogue of Innovations for Human Development: An Example of Scientific and Social Valorisation of a Country by Participative Methodology. In: Kongoli F, Wang Z, Okura T, Souza T, Silva AC, editors. Sustainable Industrial Processing Summit SIPS2018 Non-ferrous / Mineral Processing / Environmental Protection. Montreal: Flogen Star Outreach. 2018; 7: 235-236. Available from: https://www.flogen.org/sips2018/paper-7-138.html

4. Rossi D, Jobstraibizer PG, Dal Bosco C, Bettero A. A combined chemico-mineralogical and tensiometric approach for evaluation of Euganean Thermal Mud (ETM) quality. J. Adh. Sci. Tech. 2012 Jun; 27(1): 30-45.

5. Etzler F. Determination of the Surface Free Energy of Solids. In: Mittal $\mathrm{K}$ editor. Reviews of Adhesion and Adhesives. 1st ed. Beverly:Scrivener Publishing LCC; 2013.

6. Rossi D. The Quality Assessment of a Mudtherapy Protocol by Surface Tensiometry Using the Contact Angle Method: The Japanese Biofango ${ }^{\circledR}$ Therapy Experience. Int. Journ. of Wettability Science and Technology 2019; 1: 137-167.

7. Rossi D. TVS ${ }^{\circledR}$ MUD INDEX a rapid method for quality assessment of natural and artificial thermal muds. Ideass Innovation for Development and South-South Cooperation 2012

http://www.ideassonline.org/public/pdf/BrochureTVSENG.pdf

8. Bellometti S, Cecchettin M, Lalli A, Galzigna L. Mud pack treatment increases serum antioxidant defenses in osteoarthrosic patients. Biomed Pharmacother 1996; 50(1):37.

9. Portolan A. Valutazione delle proprietà di scambio del fango termale mediante TVS modeling. Department of Pharmaceutical and Pharmacological, University of Padova, Italy, Thesis Academic Year 2006/2007.

10. Pancotto C. Valutazione dell'indice di bioadesività e dell'efficacia funzionale di un fango termale mediante TVS modelling. Department of Pharmaceutical and Pharmacological, University of Padova, Italy, Thesis Academic Year 2006/2007.

11. Marcolongo G, De Appolonia F, Venzo A, Berrie CP, Carofiglio T, Berrini CC. Diacylglycerolipids isolated from a thermophile cyanobacterium from the Euganean hot springs. Nat. Prod. Res. 1996; 20(8): 766-774. 